\title{
AVALIAÇÃO DA TEMPERATURA DE BALCÕES E CÂMARAS FRIAS DE ARMAZENAMENTO DE QUEIJOS E EMBUTIDOS EM SUPERMERCADOS DA CIDADE DE BELÉM - PA (BRASIL)
}

\author{
CONSUELO L. SOUSA * \\ CLÁUDIA PUERARI FARIA $†$ \\ ELISA CRISTINA ANDRADE NEVES **
}

\begin{abstract}
Avaliou-se a adequação das temperaturas de armazenamento e exposição de queijos e embutidos em balcões refrigerados internos, externos e nas câmaras frias de setores de fatiados de dois supermercados de Belém-PA (Brasil). As temperaturas das câmaras frias e dos balcões refrigerados foram medidas com termômetro digital, sendo avaliada a média das temperaturas obtidas em cada ponto dos equipamentos. As temperaturas das câmaras frias mostraram-se adequadas em ambos os supermercados, enquanto que as temperaturas dos balcões refrigerados apresentaram variações. Foram observadas temperaturas acima da máxima permitida $\left(10^{\circ} \mathrm{C}\right)$ para comercialização de queijos e embutidos, evidenciando a necessidade de monitoramento e de regulagem dos balcões refrigerados para manutenção da qualidade dos produtos em questão.
\end{abstract}

PALAVRAS-CHAVE: PRODUTOS PERECÍVEIS; QUEIJOS; EMBUTIDOS.

\section{INTRODUÇÃO}

O setor supermercadista caracteriza-se pela mediação entre a indústria e o consumidor, sendo o elo de ligação na cadeia de comercialização de produtos alimentícios. Desta forma, também é responsável pela manutenção da qualidade dos produtos oferecidos ao consumidor.

Muitos produtos comercializados pelos supermercados são perecíveis exigindo cuidados especiais no que diz respeito à temperatura de transporte, armazenamento e exposição. Os alimentos perecíveis são

* Professora, Departamento de Engenharia Química e de Alimentos, Centro Tecnológico, Universidade Federal do Pará (DEQAL/CT/UFPA), Belém, PA (e-mail: sousa@ufpa.br).

** Aluna, Curso de Especialização, Tecnologia de Alimentos, DEQAL/CT/UFPA, Belém, PA. 
expostos em balcões refrigerados que permitem praticidade ao consumidor na escolha entre as opções oferecidas de produtos (ABRAS, 2001).

O Código de Proteção e Defesa do Consumidor garante, entre outros direitos, a proteção da vida, da saúde e a segurança contra os riscos provocados por práticas no fornecimento de produtos e serviços considerados perigosos ou nocivos (BRASIL, 1998; PRATA, 2000).

Até que seja distribuído e consumido a obtenção de produto seguro depende tanto da qualidade da matéria-prima quanto da sua manutenção. No setor de fatiados de supermercados, a qualidade envolve todos os processos que possam comprometer os padrões do produto, como: matéria-prima, transporte, equipamentos, manipulação, embalagem, armazenamento refrigerado e comercialização (SILVA JÚNIOR, 1995).

Os balcões refrigerados utilizados para expor o produto ao consumidor, no entanto, muitas vezes não atendem aos parâmetros de temperatura para o armazenamento adequado de produtos perecíveis. Constituem dessa maneira, ponto importante para o consumidor, visto que o controle desses critérios pode prevenir, reduzir ou eliminar os riscos de ocorrência de perigos de origem microbiana (ARRUDA et al., 1996; ICMSF, 1997). Segundo CHESCA et al. (2000), a temperatura do local de armazenamento é essencial, pois a velocidade das reações biológicas nos alimentos eleva-se em relação direta ao aumento de calor.

Os produtos perecíveis resfriados devem ser armazenados entre 6 e $10^{\circ} \mathrm{C}$ ou conforme especificação do fabricante. No armazenamento refrigerado, alimentos ou recipientes com alimentos não devem estar em contato com o piso, mas apoiados sobre estrados ou prateleiras, respeitando o espaçamento mínimo de $10 \mathrm{~cm}$ para garantir a circulação do ar. Os alimentos não devem ser armazenados junto com os produtos de limpeza, químicos, de higiene e perfumaria (SÃO PAULO, 1999).

Os equipamentos de refrigeração precisam ser adequados aos tipos de alimentos a serem armazenados. As câmaras frias devem apresentar antecâmara para proteção térmica (revestidas com material lavável e resistente), nível do piso igual ao da área externa, termômetro que possibilite a leitura pelo lado externo, interruptor de segurança (localizado na parte externa da câmara), lâmpada piloto indicadora ("ligado-desligado"), prateleiras em aço inox ou outro material apropriado, porta que possibilite a manutenção da temperatura interna e dispositivos de segurança que permitam abri-la por dentro quando for dotada de porta hermética (SÃO PAULO, 1999). 
Trabalhos publicados no Brasil têm evidenciado que a ausência de controle da temperatura das gôndolas dos supermercados coloca em risco a vidade-prateleira e a segurança sanitária dos produtos (MACÊDO et al., 2000; STOLTE e TONDO, 2001; BENEVIDES e TELLES, 2002).

O leite, a carne e seus derivados são produtos sujeitos a diversas alterações durante a manipulação, distribuição e comercialização no varejo. As temperaturas e cargas das gôndolas de supermercados devem ser cuidadosamente observadas, pois alguns graus a mais causam comprometimento da chamada vida-de-prateleira dos produtos (MACÊDO et al., 2000; MENDES et al., 2001).

O consumo de embutidos e queijos apresentou crescimento significativo nos últimos anos. Segundo a Associação Brasileira da Indústria de Queijo (ABIQ), em 1995 o consumo nacional de queijos de diferentes tipos cresceu $33 \%$ e a produção nacional $16 \%$ em relação a 1994. No que diz respeito à suinocultura brasileira, o volume produzido em 1999 foi de 1,7 milhão de toneladas. Cerca de $66 \%$ da produção de suínos dirigida ao mercado interno é comercializada na forma de produtos industrializados, entre os quais os embutidos (A QUANTAS..., 2000; CONSUMO DE..., 1996).

O presente trabalho teve como objetivo avaliar a temperatura de refrigeração de balcões e câmaras frias de armazenamento de queijos e embutidos em dois supermercados da cidade de Belém-PA.

\section{MATERIAL E MÉTODOS}

\subsection{CARACTERIZAÇÃO DO LOCAL}

Foram escolhidos dois supermercados da mesma rede, na cidade de Belém-PA, sendo um de grande porte localizado em centro comercial (supermercado A) e outro de médio porte localizado no bairro da Pedreira (supermercado B).

O supermercado A (grande porte) conta com setor de queijos e embutidos situado na parte posterior do estabelecimento, tendo uma câmara fria específica para armazenamento. O setor mantém um balcão refrigerado interno, do tipo estante vertical aberta, com vários níveis de prateleiras, utilizado para armazenar produtos inteiros (queijos e embutidos). Também conta com balcão refrigerado externo do tipo horizontal aberto para auto- 
serviço, no qual estão expostos os produtos fatiados (queijos e embutidos) embalados a vácuo ou em bandejas de poliestireno com filme plástico de PVC.

No supermercado B (médio porte), o setor de queijos e embutidos também está situado na parte posterior do estabelecimento e conta com uma câmara fria, um balcão refrigerado interno e um externo com as mesmas características dos equipamentos do supermercado $A$.

\subsection{ANÁLISE DAS TEMPERATURAS DOS BALCÕES REFRIGERADOS INTERNOS, EXTERNOS E DAS CÂMARAS FRIAS}

Efetuou-se a tomada de temperatura dos balcões (interno e externo) e das câmaras frias dos supermercados utilizando termômetro digital de haste Multi-Stem, com escala de -50 a $150^{\circ} \mathrm{C}$ e precisão de $0,1^{\circ} \mathrm{C}$. As tomadas de temperatura, em três pontos de cada equipamento, ocorreram sempre às $11 \mathrm{~h}$ e o procedimento de coleta de dados foi repetido durante três dias alternados.

O resultado da temperatura foi obtido pela média das três medições em cada balcão ou câmara fria e, em seguida, pela média dos resultados das três avaliações.

\section{RESULTADOS E DISCUSSÃO}

A média das temperaturas dos balcões refrigerados, obtidas nos supermercados A e B, pode ser verificada nas Tabelas 1 e 2. O padrão de temperatura ideal para queijos e embutidos é de no máximo $10^{\circ} \mathrm{C}$ (SÃO PAULO, 1999).

Observou-se ampla variação de temperatura nos diferentes pontos do mesmo balcão refrigerado. Os pontos mais críticos observados foram a parte inferior do balcão refrigerado interno e as extremidades do balcão refrigerado externo. Também ocorreram variações de uma avaliação para a outra, indicando ausência de controle efetivo das temperaturas dos balcões refrigerados.

MACÊDO et al. (2000), avaliando a temperatura de gôndolas de exposição de derivados lácteos em supermercados, observaram resultados semelhantes, com inadequação de $66 \%$ dos estabelecimentos. Trabalhos 
similares realizados pelo INMETRO e citados por tais autores mostraram problemas em cerca de $40 \%$ dos pontos de venda nos estados do Rio de Janeiro, Rio Grande do Sul e São Paulo e em $60 \%$ dos pontos de venda de Minas Gerais.

TABELA 1 - TEMPERATURAS $\left({ }^{\circ} \mathrm{C}\right)$ DOS BALCÕES REFRIGERADOS INTERNOS DOS SETORES DE QUEIJOS E EMBUTIDOS DOS SUPERMERCADOS A E B

\begin{tabular}{|c|c|c|c|c|c|c|c|c|}
\hline & \multicolumn{4}{|c|}{$\begin{array}{l}\text { Supermercado A } \\
\text { Temperatura ( C) }\end{array}$} & \multicolumn{4}{|c|}{$\begin{array}{l}\text { Supermercado B } \\
\text { Temperatura ( C) }\end{array}$} \\
\hline & \multicolumn{4}{|c|}{ Pontos avaliados } & \multicolumn{4}{|c|}{ Pontos avaliados } \\
\hline & Superior & Mediano & Inferior & MØdia & Superior & Mediano & Inferior & Mødia \\
\hline 1“ avalia ${ }^{a} 0$ & 7,9 & 8,8 & 9,0 & 8,6 & 8,5 & 7,7 & 11,8 & 9,3 \\
\hline 2" avalia ${ }^{a} 0$ & 5,8 & 5,9 & 6,2 & 6,0 & 9,8 & 9,2 & 13,9 & 11,0 \\
\hline 3“" avalia a o & 5,1 & 4,7 & 5,2 & 5,0 & 5,7 & 5,1 & 11,0 & 7,3 \\
\hline MØdia & 6,3 & 6,5 & 6,8 & - & 8,0 & 7,3 & 12,2 & - \\
\hline DP & 1,4 & 2,1 & 1,9 & 1,8 & 2,1 & 2,1 & 1,5 & 1,8 \\
\hline $\operatorname{Padr}^{a} 0(C)^{*}$ & 10,0 & 10,0 & 10,0 & 10,0 & 10,0 & 10,0 & 10,0 & 10,0 \\
\hline
\end{tabular}

* Regulamento técnico sobre os parâmetros e critérios para o controle higiênicosanitário de estabelecimentos de alimentos (SÃO PAULO, 1999).

$\mathrm{DP}=$ Desvio Padrão.

\section{TABELA 2 - TEMPERATURAS $\left({ }^{\circ} \mathrm{C}\right)$ DOS BALCÕES REFRIGERADOS EXTERNOS DOS SETORES DE QUEIJOS E EMBUTIDOS DOS SUPERMERCADOS A E B}

\begin{tabular}{|c|c|c|c|c|c|c|c|c|}
\hline & \multicolumn{4}{|c|}{$\begin{array}{l}\text { Supermercado A } \\
\text { Temperatura ( C) }\end{array}$} & \multicolumn{4}{|c|}{$\begin{array}{l}\text { Supermercado B } \\
\text { Temperatura ( C) }\end{array}$} \\
\hline & \multicolumn{4}{|c|}{ Pontos avaliados ${ }^{\star}$} & \multicolumn{4}{|c|}{ Pontos avaliados } \\
\hline & Ponto 1 & Ponto 2 & Ponto 3 & Mødia & Ponto 1 & Ponto 2 & Ponto 3 & Mødia \\
\hline 1" avalia ${ }^{a} 0$ & 13,6 & 9,8 & 8,3 & 10,6 & 16,1 & 6,3 & 10,9 & 11,1 \\
\hline 2" avalia a o & 8,7 & 8,6 & 8,8 & 8,7 & 18,6 & 9,8 & 9,7 & 12,7 \\
\hline 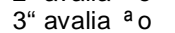 & 7,3 & 11,5 & 12,4 & 10,4 & 7,7 & 8,2 & 10,4 & 8,8 \\
\hline Media & 9,9 & 10,0 & 9,8 & - & 14,13 & 8,1 & 10,3 & - \\
\hline & 3,3 & 1,4 & 2,2 & 1,0 & 5,7 & 1,7 & 0,6 & 1,9 \\
\hline Padr $r^{a} o(C)^{\star *}$ & 10,0 & 10,0 & 10,0 & 10.0 & 10,0 & 10,0 & 10,0 & 10,0 \\
\hline
\end{tabular}

* Ponto 1 = Extremidade; Ponto 2 = Centro; Ponto 3 = Extremidade;

** Legislação em vigor (SÃO PAULO, 1999).

$\mathrm{DP}=$ Desvio Padrão.

BENEVIDES e TELLES (2002) analisaram as características microbiológicas de queijos tipo "coalho" em supermercados e no Mercado Público São Sebastião em Fortaleza (CE). Detectaram armazenamento inadequado (sem refrigeração) de $40 \%$ das amostras analisadas, evidenciando fator de risco para a população. 
As variações nos valores de temperatura dos balcões refrigerados internos e externos dos supermercados $A$ e $B$ revelam riscos para a qualidade dos produtos perecíveis armazenados nesses locais. As temperaturas acima de $10^{\circ} \mathrm{C}$ podem permitir o desenvolvimento de microrganismos patogênicos e/ou deteriorantes nos alimentos, colocando em dúvida a segurança microbiológica dos produtos e sua vida-de-prateleira (MACÊDO et al., 2000; MENDES et al., 2001).

Para manter a qualidade de produtos perecíveis é necessário que as temperaturas dos balcões refrigerados sejam mantidas em faixa aceitável (máximo $10^{\circ} \mathrm{C}$ ). Isso pode ser alcançado com o uso de termostatos aferidos para controle da temperatura, manutenção preventiva dos equipamentos e sua regulagem (MACÊDO, et al., 2000).

As temperaturas obtidas em cada balcão refrigerado dos supermercados A e B foram classificadas em três níveis (abaixo de $8^{\circ} \mathrm{C}$, entre $8^{\circ} \mathrm{C}$ e $10^{\circ} \mathrm{C}$ e acima de $10^{\circ} \mathrm{C}$ ) para verificar a porcentagem de sua ocorrência (Figuras 1 e 2).

O balcão refrigerado interno do supermercado $A$ foi o único a apresentar todos os valores de temperaturas enquadrados em faixa adequada (até $10^{\circ} \mathrm{C}$ ). No balcão refrigerado externo do supermercado $B$ foram observados valores acima do aceitável em $45 \%$ das medições, principalmente em suas extremidades.

Os balcões refrigerados interno e externo, utilizados pelos supermercados $A$ e $B$, podem apresentar problemas de transferência de calor por serem do tipo aberto. Quando a proporção de entrada de calor excede a relação de calor retirada pelo ar do balcão, a temperatura sobe. Para evitar que as temperaturas do balcão e dos produtos armazenados fiquem acima da ideal, ou que sofram variações muito grandes durante o dia, é necessário controlar a temperatura do ambiente, dotar o equipamento de termostado (devidamente regulado) e limpá-lo regularmente.

Segundo JONKE (1997) os balcões frigoríficos para auto-serviço (exposição aberta) permitem que os consumidores manipulem os produtos podendo colocar em risco sua qualidade higiênico-sanitária. O frio não destrói as bactérias, apenas retarda a multiplicação da população de microrganismos. 
FIGURA 1 - PORCENTAGEM DE OCORRÊNCIA DOS TRÊS NÍVEIS DE TEMPERATURA NOS BALCÕES REFRIGERADOS INTERNOS DOS SUPERMERCADOS A E B
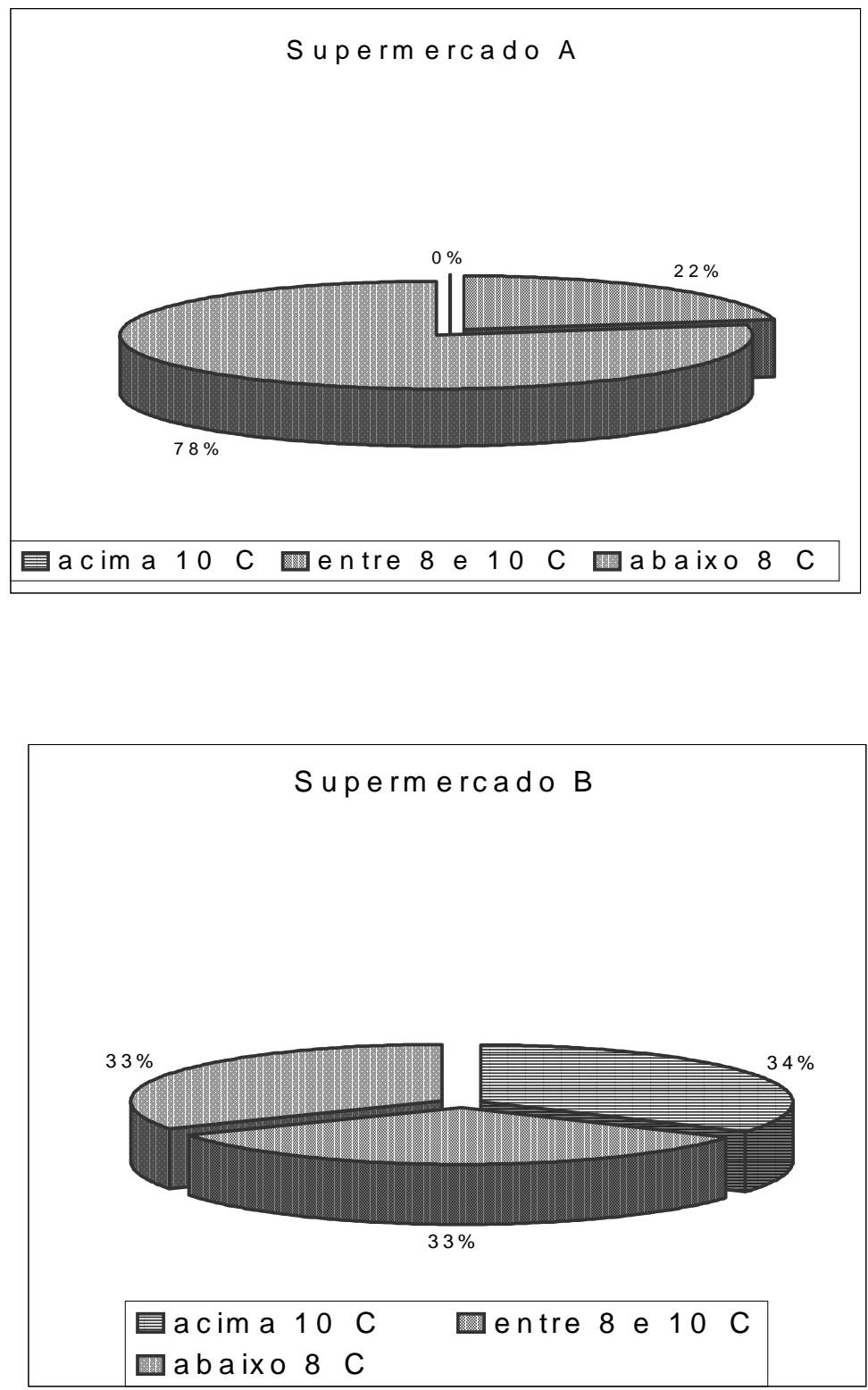
FIGURA 2 - PORCENTAGEM DE OCORRÊNCIA DOS TRÊS NÍVEIS DE TEMPERATURA NOS BALCÕES REFRIGERADOS EXTERNOS DOS SUPERMERCADOS A E B

Supermercado A

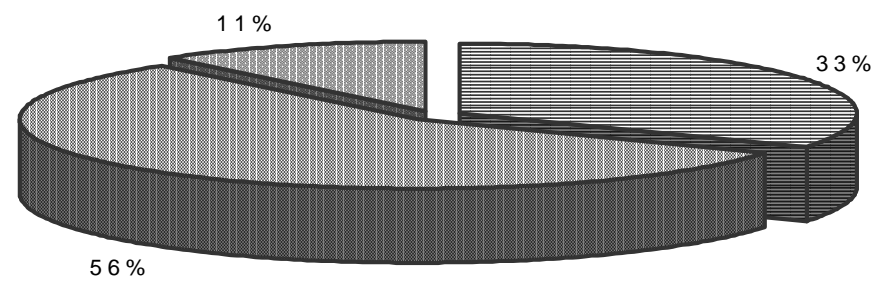

拦acim a $10 \mathrm{C}$ abaixo $8 \mathrm{C}$

$\square$ entre 8 e $10 \mathrm{C}$

Supermercado B

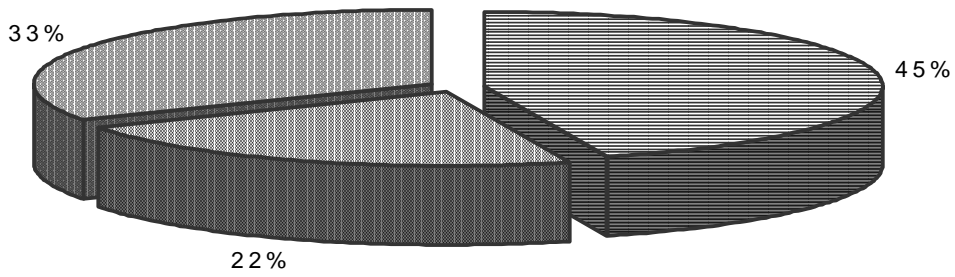

目acima 10 C 圆entre 8 e 10 C $\square$ abaixo 8 C 
A Tabela 3 indica os valores obtidos para as temperaturas das câmaras frias nas três avaliações.

\section{TABELA 3 - TEMPERATURAS $\left({ }^{\circ} \mathrm{C}\right)$ OBTIDAS NAS CÂMARAS FRIAS DOS SETORES DE QUEIJOS E EMBUTIDOS DOS SUPERMERCADOS AEB}

\begin{tabular}{|c|c|c|}
\hline Avalia ${ }^{a} 0$ & $\begin{array}{l}\text { Supermercado A } \\
\text { Temperatura ( C) }\end{array}$ & $\begin{array}{l}\text { Supermercado B } \\
\text { Temperatura ( C) }\end{array}$ \\
\hline 1"Avalia $\stackrel{a}{0}$ & 6,3 & 2,6 \\
\hline 2“Avalia $\cong$ & 6,5 & 3,2 \\
\hline 3“ Avalia $\stackrel{a}{\circ} 0$ & 6,5 & 2,0 \\
\hline MØdia & 6,4 & 2,6 \\
\hline Desvio padr ${ }^{\mathrm{a}} \mathrm{o}$ & 0,1 & 0,6 \\
\hline
\end{tabular}

As temperaturas de armazenamento nas câmaras frias dos gêneros perecíveis (queijos e embutidos), verificadas nos dois estabelecimentos, mostraram-se adequadas em todas as medições (abaixo de $10^{\circ} \mathrm{C}$ ). STOLTE e TONDO (2001) verificaram adequação da temperatura de quatro câmaras frias em Unidade de Alimentação e Nutrição, porém algumas amostragens ultrapassaram os limites estabelecidos. A manutenção das câmaras frias fechadas durante a maior parte do tempo contribuiu de forma decisiva para esses resultados. Já os balcões refrigerados tipo auto-serviço tornaram-se mais propícios à troca de calor com o ambiente (temperatura aproximada de $22^{\circ} \mathrm{C}$ ). Seria ideal colocar barreiras nesses equipamentos como, por exemplo, cortina de ar a fim de diminuir as trocas indesejáveis de calor.

\section{CONCLUSÃO}

As temperaturas de armazenamento e de exposição à venda dos queijos e embutidos apresentaram variação entre os pontos e entre as avaliações em ambos os supermercados. Os pontos mais críticos em relação à adequação da temperatura foram a parte inferior do balcão refrigerado interno e as extremidades do balcão refrigerado externo.

Apenas o balcão refrigerado interno do supermercado $A$ apresentou temperaturas adequadas em todas as medições e posições mensuradas. 
As temperaturas das câmaras frias dos supermercados A e B mostraramse adequadas em todas as medições.

Para alcançar a temperatura adequada para os produtos perecíveis (máximo $10^{\circ} \mathrm{C}$ ) é necessário o monitoramento e controle das temperaturas dos balcões refrigerados, bem como a regulagem desses equipamentos.

\section{Abstract}

TEMPERATURE EVALUATION OF BALCONIES AND COLD CHAMBERS FOR CHEESE AND COLD CUTS STORAGE AT SUPERMARKETS IN THE CITY OF BELÉM-PA (BRAZIL)

The temperature adequation of storage and exposure of cheese and cold cuts in internal and external cold balconies and in the cold chamber from sliced section of two supermarkets, in the city of Belém - PA (Brazil) were evaluated. The temperatures of the cold chamber and refrigerated balconies were measured using a digital thermometer, and it was evaluated the average of temperatures obtained in each point of the equipments. The temperatures of cold chambers were adequate in both supermarkets, however, the temperatures of refrigerated balconies showed variations. Temperatures above the maximum allowed $\left(10^{\circ} \mathrm{C}\right)$ for the commercialization of cheese and cold cuts were observed, evidencing the need to monitor and to regulate cold balconies for maintenance of the products quality.

KEY-WORDS: PERISHABLE-PRODUCTS; CHEESE; COLD CUTS.

\section{REFERÊNCIAS}

1 A QUANTAS anda a indústria de suínos: o Brasil promove mudanças e consegue aumentar o consumo interno e exportação. Revista do Açougueiro \& Frigorífico, v. 6, n. 62, p.27-32, set. 2000.

2 ABRAS. Associação Brasileira de Supermercados. Sobre a região norte. Disponível em:<http://abrasnet.com.br>. Acesso em 01/02/ 2002.

3 ARRUDA, G.A.; POPOLIM, W.D.; FUJINO, H.; LEITE, C.L.; RIBEIRO, L.C. Avaliação das condições de entrega de gêneros perecíveis em unidade de alimentação e nutrição, através do método de Análise de Perigos em Pontos Críticos de Controle (APPCC). Revista Higiene Alimentar, v.10, n.44, p. 44-48, 1996.

4 BENEVIDES, S.D.; TELLES, F.J.S. Características microbiológicas, de armazenamento e de embalagem de queijos tipo "coalho" comercializados na cidade de Fortaleza, CE. Revista Higiene 
Alimentar, v.16, n. 95, p. 44-47, 2002.

5 BRASIL. Ministério da Justiça. Lei 8078, de 11 de setembro de 1990. Dispõe sobre a proteção do consumidor e dá outras providências. Brasília: Nova e Atual, 1998. 62p.

6 CHESCA, A.C.; TEIXEIRA, A. A.; COSTA, C.D.C.; OLIVEIRA,M.; ARAÚJO, M.D.C.; VALE, M.D.C.; VANCIN, V.C.; OKURA, M.H. Avaliação da temperatura das estufas de salgados de bares e lanchonetes do município de Uberaba, MG. Revista Higiene Alimentar, v.14, n.78/79, p. 87-89, 2000.

7 CONSUMO de queijo no Brasil cresceu 33\%: país registra o maior índice de importação de sua história. Leite e Derivados, v. 5, n.27, p.46-51, 1996.

8 ICMSF. International Commission on Microbiological Specifications for Foods. Análise de perigos e pontos críticos de controle na qualidade e segurança microbiológica de alimentos. São Paulo: Varela, 1997.

9 JONKE, L. A.C. Refrigeração no varejo da carne: a última etapa da cadeia do frio. Revista Nacional da Carne, n.247, p.44-60, 1997.

10 MACÊDO, J. A.B. de; AMORIM, J.M.; LIMA, D.C.; SILVA, P.M.; VAZ, U.P. Avaliação da temperatura de refrigeração nas gôndolas de exposição de derivados lácteos em supermercados da região de Juiz de Fora/MG. Revista Leite e Derivados, n. 53, p.20-30, 2000.

11 MENDES, A.C.R.; SANTANA NETA, L.G.; COSTA, D.S.; ALMEIDA, J.F. Condições de comercialização de cortes cárneos em supermercados da cidade de Salvador, BA. Aspectos higiênicosanitários e de conservação. Revista Higiene Alimentar, v.15, n.83, p.58-62, 2001.

12 PRATA, L.F. Higiene de alimentos e as necessidades contemporâneas. Revista Higiene Alimentar, v. 14, n. 74, p.1316, 2000.

13 SÃO PAULO. Centro de Vigilância Sanitária da Secretaria de Estado da Saúde. Portaria n. ${ }^{\circ}$ 06, de 10 de março de 1999. Regulamento Técnico sobre os Parâmetros e Critérios para o Controle HigiênicoSanitário em Estabelecimentos de Alimentos. Diário Oficial do Estado de São Paulo, São Paulo, 10 de março de 1999. 
14 SILVA JÚNIOR, E. A. Manual de controle higiênico-sanitário em alimentos. 2.ed. São Paulo: Varela, 1995.

15 STOLTE, D.; TONDO, E.C. Análise de perigos e pontos críticos de controle em uma unidade de alimentação e nutrição. Revista Higiene Alimentar, v. 15, n. 85, p.41-49, 2001. 